Article

\title{
Profiling and Characterization of Volatile Components from Non-Fumigated and Sulfur-Fumigated Flos Lonicerae Japonicae Using Comprehensive Two-Dimensional Gas Chromatography Time-of-Flight Mass Spectrometry Coupled with Chemical Group Separation
}

\author{
Hao Cai ${ }^{1,2,3, \dagger * *}$, Gang Cao ${ }^{2,3,4, \dagger}$, Li Li ${ }^{5, \dagger}$, Xiao Liu ${ }^{1,2,3}$, Xiao-Qing Ma ${ }^{1,2}$, Si-Cong Tu ${ }^{6}$, \\ Ya-Jing Lou ${ }^{1,2}$, Kun-Ming Qin ${ }^{1,2}$, Song-Lin $\mathrm{Li}^{7}$ and Bao-Chang Cai ${ }^{1,2,3,4, *}$
}

1 Department of Chinese Materia Medica, College of Pharmacy,

Nanjing University of Chinese Medicine, Nanjing 210023, China

2 Engineering Center of State Ministry of Education for Standardization of Chinese Medicine Processing, Nanjing University of Chinese Medicine, Nanjing 210023, China

3 National First-Class Key Discipline for Science of Chinese Materia Medica, Nanjing University of Chinese Medicine, Nanjing 210023, China

4 Research Center of TCM Processing Technology, Zhejiang Chinese Medical University, Hangzhou 310053, China

5 LECO Corporation Shanghai Representative Office, Shanghai 201900, China

6 Faculty of Medicine, University of New South Wales, Sydney, NSW 2031, Australia

7 Department of Pharmaceutical Analysis and Metabolomics, Jiangsu Province Academy of Chinese Medicine, Nanjing 210028, China

$\dagger$ These authors contributed equally to this work.

* Authors to whom correspondence should be addressed: E-Mails: haocai_98@126.com (H.C.); bccai@126.com (B.-C.C.); Tel./Fax: +86-25-8679-8281.

Received: 25 October 2012; in revised form: 10 January 2013 / Accepted: 14 January 2013 / Published: 24 January 2013

Abstract: Flos Lonicerae Japonicae (FLJ) is a popular herb used for many centuries in Traditional Chinese Medicine as a treatment of fever and inflammation. Non-fumigated processing of FLJ has been the traditional approach used in post-harvest preparation of the commodity for commercial use. However, in recent years, natural drying processing of FLJ has been replaced by sulfur-fumigation for efficiency and pest control. Sulfur-fumigation can induce changes in the volatile compounds of the herb, altering its medicinal properties. 
A comprehensive two-dimensional gas chromatography time-of-flight mass spectrometry ( $\mathrm{GC} \times \mathrm{GC}-\mathrm{TOF} / \mathrm{MS})$ method was established for the resolution and determination of volatile components in non-fumigated and sulfur-fumigated FLJ. In this paper, analysis of the volatile oils in non-fumigated and sulfur-fumigated (including lab-prepared sulfurfumigated and industrial sulfur-fumigated) FLJ was performed using GC×GC-TOF/MS. Seventy-three representative volatile components were identified, including furans, alkalies, acids, aldehydes, ketones, alcohols, terpenes, esters, and others, as the main components of FLJ volatile oils. The proposed method was successfully applied for rapid and accurate quality evaluation of FLJ and its related medicinal materials and preparations.

Keywords: sulfur-fumigation; GC $\times \mathrm{GC}-\mathrm{TOF} / \mathrm{MS}$; volatile compounds; Flos Lonicerae Japonicae; quality control

\section{Introduction}

Flos Lonicerae Japonicae (FLJ) is derived from the dried flower buds of Lonicera japonica Thunb and is a popular medicinal herb used in Traditional Chinese Medicine (TCM). FLJ is known to exhibit a wide spectrum of biological and pharmacological activities, such as antibacterial, anti-inflammatory, antipyretic, antioxidant, antiviral, and hepato-protective effects [1,2]. As a result, FLJ is widely used as a health-care product or consumed in the form of herbal tea. Furthermore, FLJ contains significant amounts of organic acids, flavonoids, volatile oils, iridoid glycosides and saponins that are considered to be the biologically active components critical in many TCM formulas [3,4].

Traditionally, the roots, flowers and rhizomes used in TCM were dried naturally under the sun. However, in recent decades, this practice has been replaced by sulfur-fumigation, a faster and cheaper method for prevention against insects and mould formation during storage [5]. Typically, this process involves the product being placed in the upper levels of a closed chamber while sulfur powder is burnt at the bottom of the chamber overnight. Sulfur dioxide is then released into the chamber and penetrates the herb. Sulfur-fumigation was recently reported to cause chemical transformation of bioactive components in herbs or its extracts, consequently altering bioactivities, pharmacokinetics, or even the toxicity of TCM [6]. In FLJ, post-harvest processing of the flowering head has traditionally involved natural drying processes. In recent years it has been reported that farmers and wholesalers have replaced this process with sulfur-fumigation. To the best of our knowledge, there has been no investigation into the influence of sulfur-fumigation on volatile components of FLJ.

In the past few years, quality evaluations of FLJ and its preparations have been performed by using many analytical techniques including thin layer chromatography (TLC), gas chromatography (GC), high-performance liquid chromatography (HPLC) and liquid chromatography-mass spectrometry (LC-MS) [7-10]. However, the previous studies have mainly focused on the components of FLJ, such as organic acids, iridoid glycosides, flavonoids and saponins. It appears that study into the chemical compositions of the essential oils of FLJ has largely been overlooked [11,12]. Characterization of the volatile compounds of FLJ could be used as an indicator of the identity and the quality of FLJ. Furthermore, the volatile organic constituents of FLJ may contribute to some of the pharmacological 
effects of FLJ extracts. As a typical format of multi-dimensional separation system, comprehensive two-dimensional gas chromatography time-of-flight mass spectrometry (GC $\times \mathrm{GC}-\mathrm{TOF} / \mathrm{MS}$ ) has become an attractive approach for the analyses of volatile oils in TCM at low concentration in a shorter analytical period $[13,14]$. GC $\times \mathrm{GC}$ offers greater peak capacity for a complex sample, which can be achieved by combining a long column as the first dimension with a short column in the second dimension, to spread analytes over a second dimension separation space according to orthogonality considerations. The addition of TOF/MS provides a sensitive detector with full-scan MS capability and a high data density in the second dimension separation space $[15,16]$. In particular, GC $\times \mathrm{GC}$ connected to MS with time-of-flight (TOF) analyzer is showing specific advantages in providing accurate mass analysis, resolving power, enhanced selectivity, and high-throughput screening for analysis of complex matrixes such as volatile oils $[17,18]$. These advantages allow unequivocal identification of ingredients with low quantities, as well as the possibility of quantitation at low concentration levels using extracted ion chromatograms. Up to now, several GC $\times \mathrm{GC}$ methods have been successfully established for qualitative and quantitative analysis of volatile components in TCM in our laboratory. However, to our knowledge, no strategy has been presented for rapid screening and identification of volatile components from non-fumigated and sulfur-fumigated FLJ using combined techniques of GC $\times \mathrm{GC}$ separation with TOF/MS approaches.

In this study, an integrated approach using GC $\times$ GC-TOF/MS with chemical group separation was established and applied for the resolution and determination of volatile components in non-fumigated and sulfur-fumigated FLJ. GC $\times$ GC-TOF/MS was employed to detect the corresponding molecular weight of volatile components. In total, nine groups of volatile components, including furans, alkalies, acids, aldehydes, ketones, alcohols, terpenes, esters and others, were identified for profiling and evaluating the non-fumigated and sulfur-fumigated FLJ samples. This method could be applied to rapidly discriminate sulfur-fumigated FLJ among commercial samples.

\section{Results and Discussion}

\subsection{Qualitative Analyses of Non-Fumigated and Sulfur-Fumigated Flos Lonicerae Japonicae Volatile Oils}

Based on GC $\times \mathrm{GC}-\mathrm{TOF} / \mathrm{MS}, 73$ representative volatile components with match quality greater than $80 \%$ in non-fumigated and sulfur-fumigated FLJ were detected. Generally, the first chromatographic column is non-polar, and the second one is medium-polar. The GC×GC system accomplishes true orthogonal separation due to the changes in polarities of two fixed phases and the linear temperature programming.

The volatile fractions of non-fumigated and sulfur-fumigated FLJ essential oils normally contain several classes of compounds that vary over a wide range of concentrations. The compositions of the volatile fractions obtained from non-fumigated and sulfur-fumigated FLJ using the GC×GC-TOF/MS technique are summarized in Table 1. The volatile fractions are characterized by high percentages of furans, alkalies, acids, aldehydes, ketones, alcohols, terpenes, and esters. These components contribute mainly to the fragrance of non-fumigated and sulfur-fumigated FLJ volatile oils. It should be noted that the peak identification of components is based on NIST08, Adams and Wiley6 mass spectra database 
libraries. Consequently, the quality of FLJ volatile oils can be assessed by comparing the contents of these compounds. With non-fumigated FLJ samples as a reference, the major portion of volatile components in sulfur-fumigated FLJ was lower than that in non-fumigated ones. After sulfur-fumigation, the components including alkalies and most acids were not found in FLJ. It has been reported that FLJ volatile oils display antibacterial, anti-inflammatory, analgesic, antitumor activities, and also have anti-tussive and anti-asthmatic effects.

Table 1. 73 representative volatile components identified in non-fumigated and sulfur-fumigated Flos Lonicerae Japonicae by GC×GC-TOF/MS.

\begin{tabular}{|c|c|c|c|c|c|c|c|}
\hline \multirow{2}{*}{ Group } & \multirow{2}{*}{ Name } & \multirow{2}{*}{ R.T. (s) } & \multirow{2}{*}{$\begin{array}{l}\text { Quant } \\
\text { Masses }\end{array}$} & \multirow{2}{*}{ Similarity } & \multirow{2}{*}{$\begin{array}{c}\text { Non-Fumigated } \\
\text { Sample }(\%)\end{array}$} & \multicolumn{2}{|c|}{ Sulfur-Fumigated Sample } \\
\hline & & & & & & Lab-Prepared (\%) & Industrial (\%) \\
\hline \multirow{2}{*}{ Furans } & Furan, 2-ethyl- & $312,1.200$ & 81 & 876 & 100 & 45.41 & 45.60 \\
\hline & Furan, 2-pentyl- & $498,1.330$ & 81 & 891 & 100 & 71.64 & 41.25 \\
\hline \multirow{4}{*}{ Alkalies } & Pyridine & $342,1.400$ & 52 & 955 & 100 & ND & ND \\
\hline & Pyridine, 3-ethyl- & $480,1.480$ & 92 & 943 & 100 & ND & ND \\
\hline & Pyridine, 3-ethenyl- & $486,1.510$ & 104 & 898 & 100 & ND & ND \\
\hline & Isoquinoline & $684,2.090$ & 129 & 935 & 100 & ND & ND \\
\hline \multirow{10}{*}{ Acids } & $n$-Decanoic acid & $732,1.680$ & 60 & 920 & 100 & 29.81 & ND \\
\hline & Dodecanoic acid & $888,2.120$ & 60 & 925 & 100 & ND & 4.03 \\
\hline & Tetradecanoic acid & $1110,2.560$ & 60 & 909 & 100 & 0.09 & 0.32 \\
\hline & Pentadecanoic acid & $1260,2.650$ & 60 & 883 & 100 & ND & ND \\
\hline & $\begin{array}{c}\text { (Z)-11-Hexadecenoic } \\
\text { acid }\end{array}$ & $1380,3.020$ & 55 & 919 & 100 & 52.46 & 0.80 \\
\hline & $n$-Hexadecanoic acid & $1404,3.070$ & 87 & 935 & 100 & ND & ND \\
\hline & Heptadecanoic acid & $1554,2.930$ & 73 & 845 & 100 & ND & ND \\
\hline & Linoleic acid & $1656,3.540$ & 81 & 952 & 100 & ND & 0.32 \\
\hline & $\begin{array}{c}\text { trans-13-Octadecenoic } \\
\text { acid }\end{array}$ & $1668,3.270$ & 98 & 860 & 100 & ND & 5.10 \\
\hline & Linolenic acid & $1668,3.690$ & 79 & 923 & 100 & 13.61 & 24.16 \\
\hline \multirow{11}{*}{ Aldehydes } & Hexanal & $366,1.280$ & 56 & 901 & 100 & 75.46 & 26.89 \\
\hline & Furfural & $396,1.480$ & 96 & 969 & 100 & ND & 87.18 \\
\hline & (E)-2-Hexenal & $402,1.370$ & 55 & 955 & 100 & ND & ND \\
\hline & Heptanal & $438,1.320$ & 70 & 916 & 100 & 39.42 & 46.60 \\
\hline & $\begin{array}{l}\text { 2-Furancarboxaldehyde, } \\
\text { 5-methyl- }\end{array}$ & $480,1.540$ & 110 & 933 & 100 & 113.20 & 247.31 \\
\hline & Benzaldehyde & $486,1.540$ & 106 & 971 & 100 & 5.63 & 1.78 \\
\hline & Lilac aldehyde C & $600,1.490$ & 55 & 931 & 100 & ND & ND \\
\hline & $\begin{array}{l}\text { Benzaldehyde, } \\
\text { 2,4-dimethyl- }\end{array}$ & $648,1.770$ & 133 & 932 & 100 & 128.03 & 109.54 \\
\hline & $\begin{array}{l}\text { Benzaldehyde, } \\
\text { 2,4,5-trimethyl- }\end{array}$ & $750,2.220$ & 147 & 891 & 100 & 57.75 & ND \\
\hline & Hexadecanal & $1062,2.340$ & 82 & 946 & 100 & 136.70 & 83.14 \\
\hline & Farnesal & $1098,2.920$ & 84 & 947 & 100 & 11.34 & 3.89 \\
\hline
\end{tabular}


Table 1. Cont.

\begin{tabular}{|c|c|c|c|c|c|c|c|}
\hline \multirow{2}{*}{ Group } & \multirow{2}{*}{ Name } & \multirow{2}{*}{ R.T. (s) } & \multirow{2}{*}{$\begin{array}{l}\text { Quant } \\
\text { Masses }\end{array}$} & \multirow{2}{*}{ Similarity } & \multirow{2}{*}{$\begin{array}{c}\text { Non-Fumigated } \\
\text { Sample (\%) } \\
\end{array}$} & \multicolumn{2}{|c|}{ Sulfur-Fumigated Sample } \\
\hline & & & & & & Lab-Prepared (\%) & Industrial (\%) \\
\hline \multirow{10}{*}{ Ketones } & 2-Heptanone & $426,1.330$ & 58 & 882 & 100 & 30.03 & 65.47 \\
\hline & 1,3-Isobenzofurandione & $714,2.390$ & 76 & 965 & 100 & 4.06 & ND \\
\hline & Piperitenone & $732,2.140$ & 150 & 907 & 100 & ND & 8.42 \\
\hline & cis-Jasmone & $768,2.210$ & 79 & 931 & 100 & ND & ND \\
\hline & Geranylacetone & $798,2.000$ & 69 & 950 & 100 & 59.93 & 7.69 \\
\hline & $\beta$-Ionone & $834,2.300$ & 177 & 897 & 100 & 51.73 & 9.90 \\
\hline & 2,3-Dehydro- $\alpha$-ionone & $834,2.360$ & 175 & 881 & 100 & 29.24 & 19.16 \\
\hline & $\begin{array}{c}\text { 1(3H)-Isobenzofuranone, } \\
\text { 3-butylidene- }\end{array}$ & $1038,3.600$ & 159 & 953 & 100 & 92.08 & 4.73 \\
\hline & 2-Pentadecanone & $1044,2.320$ & 58 & 943 & 100 & 89.67 & 27.81 \\
\hline & Muskolactone & $1380,3.680$ & 83 & 913 & 100 & 103.80 & 127.84 \\
\hline \multirow{12}{*}{ Alcohols } & Linaool & $564,1.360$ & 71 & 954 & 100 & 12.21 & 22.83 \\
\hline & Ho-trienol & $570,1.380$ & 82 & 931 & 100 & ND & 38.17 \\
\hline & $p$-Mentha-1,5-dien-8-ol & $618,1.520$ & 59 & 890 & 100 & ND & 9.39 \\
\hline & 4-terpineol & $624,1.510$ & 71 & 927 & 100 & 19.66 & 48.30 \\
\hline & Geraniol & $660,1.590$ & 69 & 959 & 100 & ND & 12.07 \\
\hline & 3-Allylguaiacol & $738,2.080$ & 164 & 951 & 100 & 14.37 & 17.29 \\
\hline & $\alpha$-ionol & $750,1.830$ & 95 & 868 & 100 & ND & ND \\
\hline & Nerolidol & $900,2.170$ & 69 & 939 & 100 & 62.60 & 29.50 \\
\hline & Ledol & $1038,3.000$ & 71 & 840 & 100 & 3.11 & ND \\
\hline & $\alpha$-Bisabolol & $1044,2.680$ & 69 & 929 & 100 & 20.02 & 8.65 \\
\hline & trans-Farnesol & $1068,2.770$ & 69 & 942 & 100 & 42.09 & 35.50 \\
\hline & Isophytol & $1374,2.490$ & 71 & 935 & 100 & 594.57 & 910.91 \\
\hline \multirow{5}{*}{ Terpenes } & $\alpha$-Myrcene & $492,1.300$ & 93 & 925 & 100 & 11.66 & ND \\
\hline & trans-Caryophyllene & $798,1.900$ & 133 & 953 & 100 & ND & ND \\
\hline & $\beta$-Farnesene & $804,1.810$ & 69 & 947 & 100 & 2.14 & 0.50 \\
\hline & Curcumene & $834,2.080$ & 132 & 946 & 100 & 11.79 & 0.33 \\
\hline & Cedrene & $1158,3.100$ & 119 & 881 & 100 & 37.02 & 30.67 \\
\hline \multirow{8}{*}{ Esters } & Endobornyl acetate & $690,1.680$ & 95 & 957 & 100 & ND & ND \\
\hline & Hexyl tiglate & $708,1.660$ & 101 & 925 & 100 & 35.61 & ND \\
\hline & Benzyl tiglate & $846,2.600$ & 83 & 950 & 100 & ND & ND \\
\hline & $\begin{array}{l}\text { Tetradecanoic acid, } \\
\text { methyl ester }\end{array}$ & $1068,2.330$ & 74 & 930 & 100 & 100.46 & 246.35 \\
\hline & 2-Ethylhexyl salicylate & $1188,3.000$ & 120 & 847 & 100 & 81.39 & 13.35 \\
\hline & $\begin{array}{l}\text { Pentadecanoic acid, } \\
\text { methyl ester }\end{array}$ & $1200,2.490$ & 74 & 884 & 100 & 140.60 & 382.27 \\
\hline & Diisobutyl phthalate & $1254,3.940$ & 149 & 942 & 100 & 47.86 & 17.20 \\
\hline & $\begin{array}{c}\text { Hexadecanoic acid, } \\
\text { 3-hydroxy-, methyl ester }\end{array}$ & $1266,2.890$ & 103 & 920 & 100 & 47.04 & 16.10 \\
\hline
\end{tabular}


Table 1. Cont.

\begin{tabular}{|c|c|c|c|c|c|c|c|}
\hline \multirow{2}{*}{ Group } & \multirow{2}{*}{ Name } & \multirow{2}{*}{ R.T. (s) } & \multirow{2}{*}{$\begin{array}{l}\text { Quant } \\
\text { Masses }\end{array}$} & \multirow{2}{*}{ Similarity } & \multirow{2}{*}{$\begin{array}{c}\text { Non-Fumigated } \\
\text { Sample }(\%) \\
\end{array}$} & \multicolumn{2}{|c|}{ Sulfur-Fumigated Sample } \\
\hline & & & & & & Lab-Prepared (\%) & Industrial (\%) \\
\hline \multirow{8}{*}{ Esters } & $\begin{array}{c}\text { Benzoic acid, } \\
\text { 2-phenylethyl ester }\end{array}$ & $1266,4.540$ & 104 & 955 & 100 & 79.55 & 14.85 \\
\hline & $\begin{array}{l}\text { (Z)-7-Hexadecenoic } \\
\text { acid, methyl ester }\end{array}$ & $1326,2.800$ & 74 & 865 & 100 & 111.59 & 188.94 \\
\hline & $\begin{array}{l}\text { Hexadecanoic acid, } \\
\text { methyl ester }\end{array}$ & $1338,2.660$ & 74 & 937 & 100 & 152.72 & 341.14 \\
\hline & $\begin{array}{c}\text { Hexadecanoic acid, ethyl } \\
\text { ester }\end{array}$ & $1440,2.690$ & 88 & 902 & 100 & 265.86 & 331.69 \\
\hline & $\begin{array}{c}\text { Linolelaidic acid, methyl } \\
\text { ester }\end{array}$ & $1596,3.190$ & 81 & 935 & 100 & 104.25 & 362.59 \\
\hline & $\begin{array}{l}\text { Hexadecanoic acid, } \\
\text { 15-methyl-, methyl ester }\end{array}$ & $1644,2.860$ & 74 & 908 & 100 & 135.10 & 436.97 \\
\hline & $\begin{array}{l}\text { Octadecanoic acid, } \\
\text { methyl ester }\end{array}$ & $1956,2.990$ & 74 & 870 & 100 & 139.39 & 320.32 \\
\hline & $\begin{array}{c}\text { Eicosanoic acid, methyl } \\
\text { ester }\end{array}$ & $2256,3.320$ & 74 & 919 & 100 & ND & ND \\
\hline \multirow{3}{*}{ Others } & (-)-Caryophyllene oxide & $954,2.610$ & 107 & 869 & 100 & 2.44 & 0.45 \\
\hline & $\begin{array}{c}\text { Butylated } \\
\text { hydroxytoluene }\end{array}$ & $852,2.260$ & 205 & 861 & 100 & 33.22 & 19.69 \\
\hline & $\begin{array}{l}\text { Acetamide, } \\
N, N \text {-dimethyl- }\end{array}$ & $414,1.530$ & 87 & 962 & 100 & 167.00 & 225.95 \\
\hline
\end{tabular}

ND: Not detected.

Due to the current gaps in knowledge regarding the active components in FLJ volatile oils, further biological research is required to confirm the results of this study. Thus, it is necessary to control the main volatile target compounds in FLJ through good agricultural practice and traditional processing methods to maintain the quality of Chinese herbal medicines.

\subsection{Chemical Group Separation of Non-Fumigated and Sulfur-Fumigated Flos Lonicerae Japonicae Volatile Oils}

The column system is orthogonal and provides structured separation. Thus, nine types of components of FLJ volatile oils were detected. The chromatographic peak data consisted of first dimension retention times, second dimension retention times and peak volumes (TIC). The GC $\times \mathrm{GC}$ chromatogram was constructed as a rasterized image of the TIC computed from each secondary chromatogram (Figure 1). Based on GC $\times$ GC-TOF/MS, it can be elucidated that the peaks in the different colored balls are classified for furans, alkalies, acids, aldehydes, ketones, alcohols, terpenes, esters, and others, respectively. The relative content of each component in fumigated sample was compared with non-fumigated sample and the results are shown in Figure 2. It was found that the FLJ volatile oils were constituted by a lot of saturated and unsaturated cyclic hydrocarbons and oxygenated compounds. 
Figure 1. GC $\times$ GC-TOF/MS contour plots and three-dimensional chromatograms of non-fumigated (A/B), lab-prepared sulfur-fumigated (C/D) and industrial sulfur-fumigated (E/F) Flos Lonicerae Japonicae volatile oils. Peak identification information is provided in Table 1.
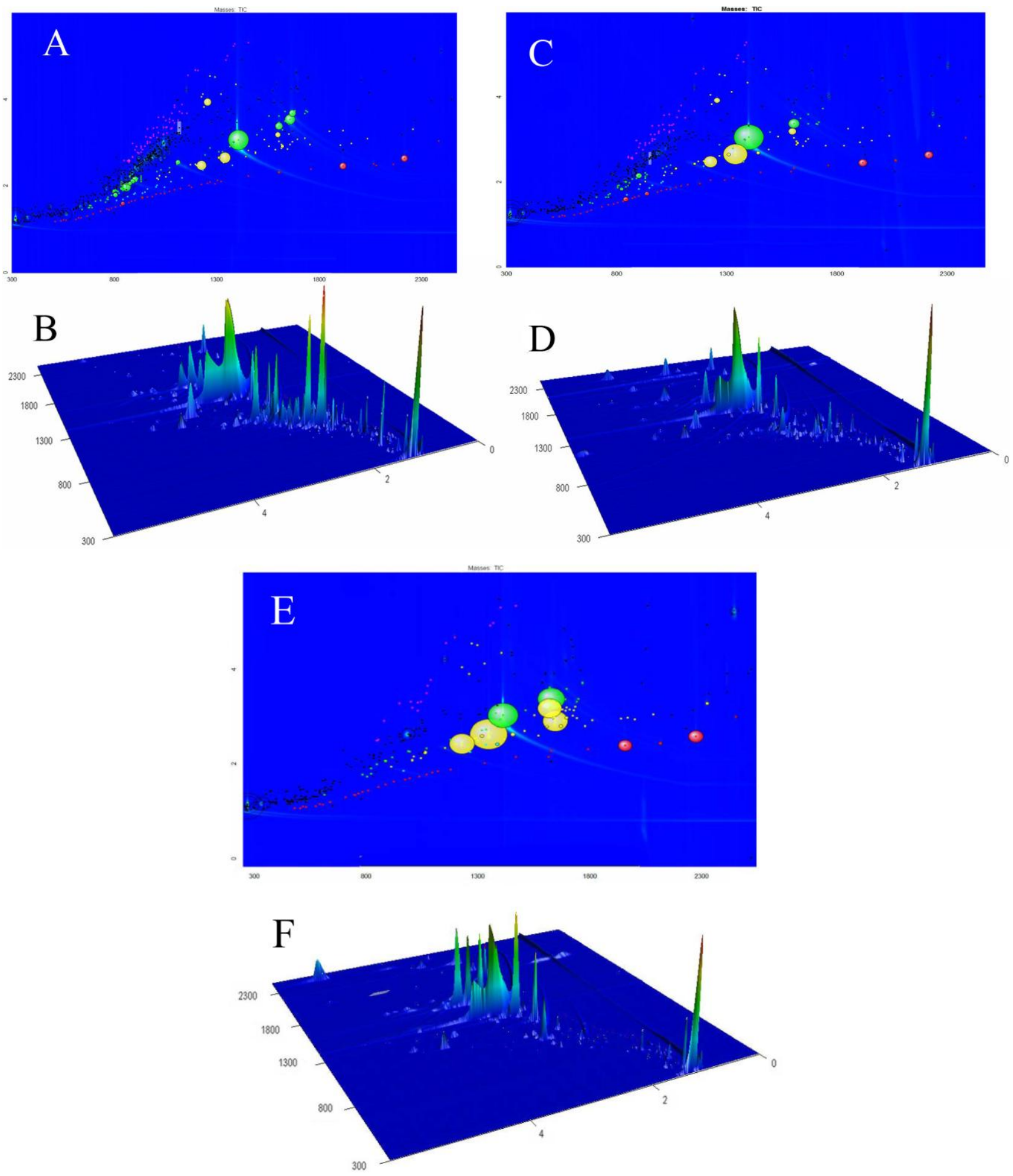
Figure 2. Comparison of the contents of major components in non-fumigated, lab-prepared sulfur-fumigated and industrial sulfur-fumigated Flos Lonicerae Japonicae volatile oils.
(A) Furans,
(B) Alkalies,
(C) Acids,
(D) Aldehydes,
(E) Ketones,
(F) Alcohols,
(G) Terpenes, (H) Esters and (I) Others.

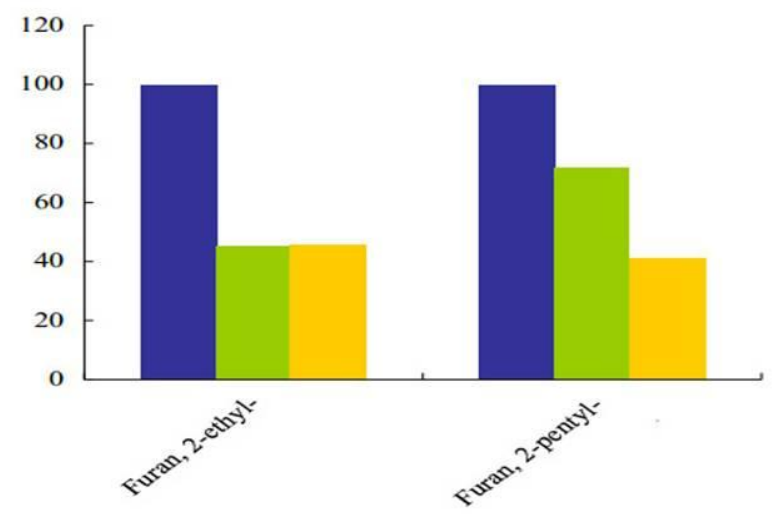
- Non-fumigated sample
Lab-prepared sulfur-fumigated sample
Industrial sulfur-fumigated
sample

A

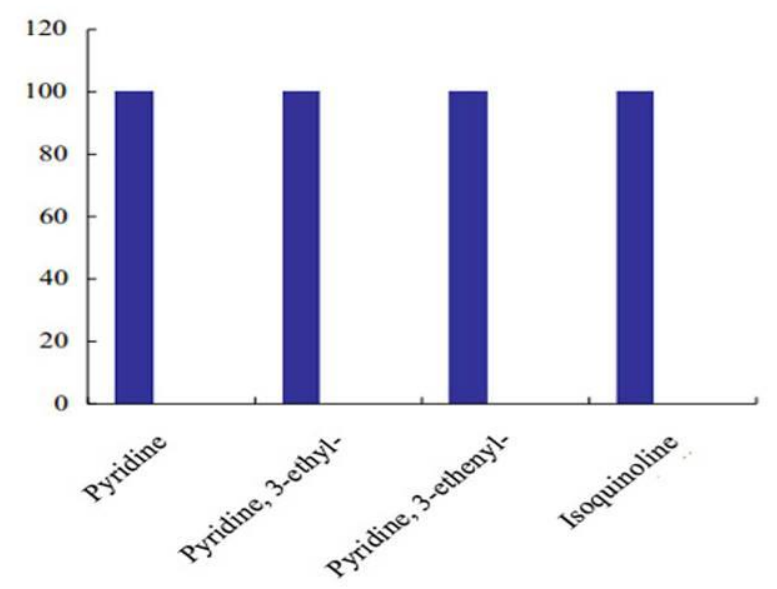

non-fumigated sample

Lab-prepared sulfur-fumigated sample

Industrial sulfur-fumigated sample

\section{B}

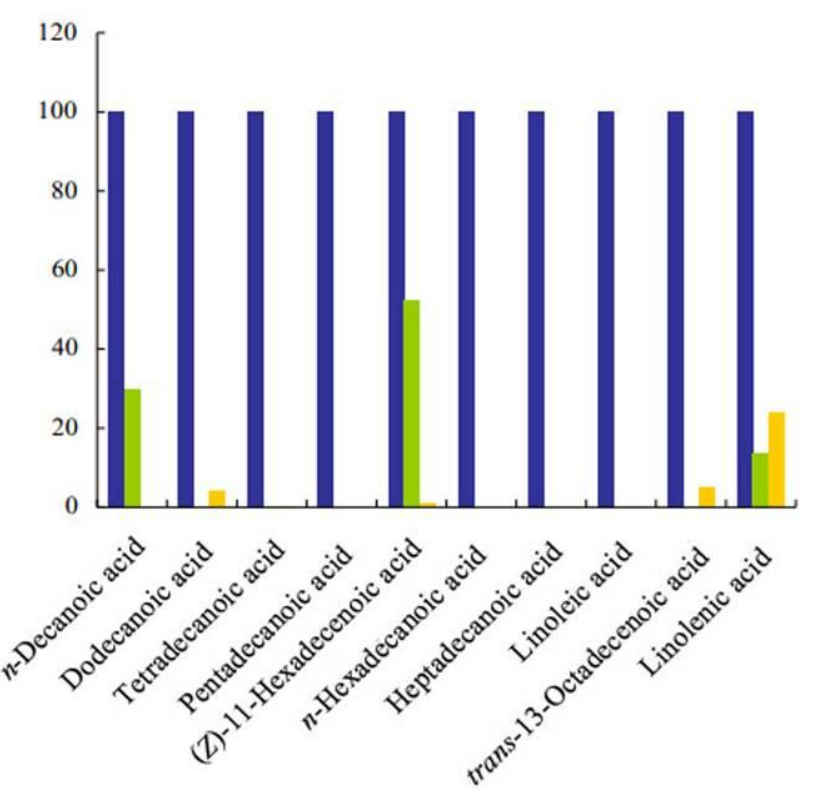

non-fumigated sample

Lab-prepared sulfur-fumigated sample

Industrial sulfur-fumigated sample

C 
Figure 2. Cont.

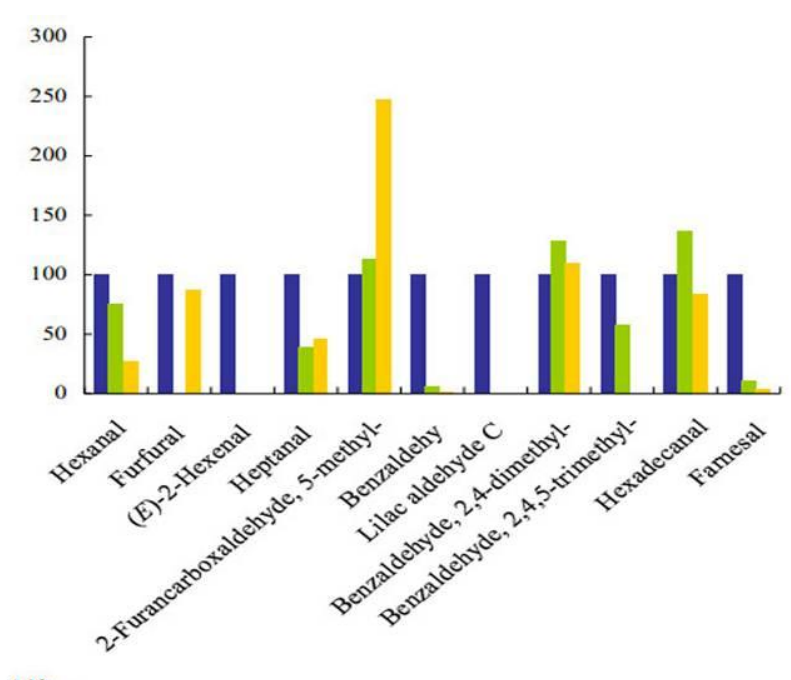

$$
\begin{aligned}
& \text { Non-fumigated sample } \\
& \text { Lab-prepared sulfur-fumigated } \\
& \text { sample } \\
& \text { Industrial sulfur-fumigated } \\
& \text { sample }
\end{aligned}
$$

D

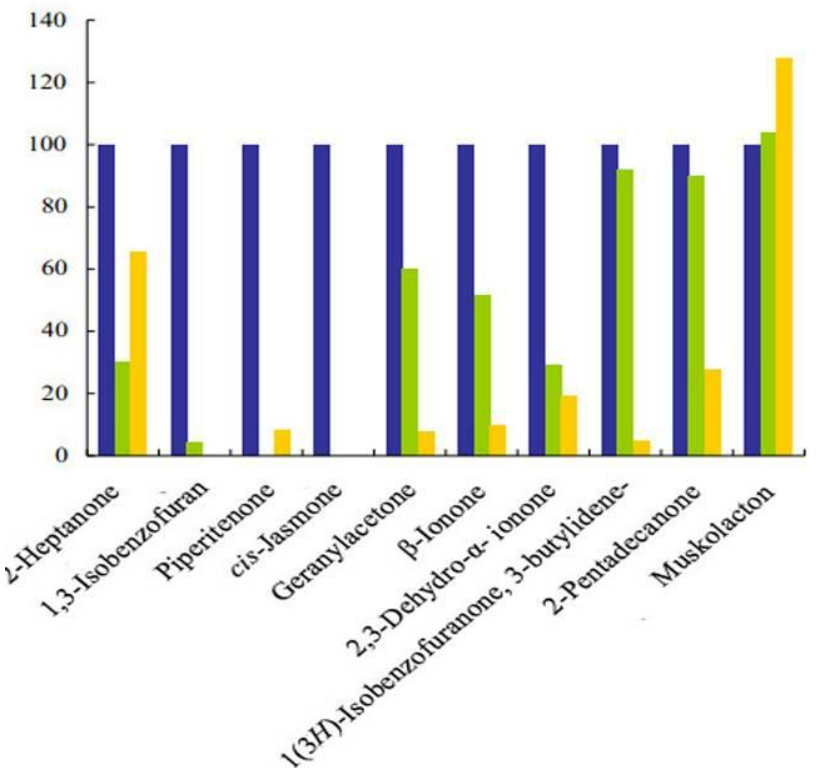

- Non-fumigated sample

Lab-prepared sulfur-fumigated sample

Industrial sulfur-fumigated

sample

E

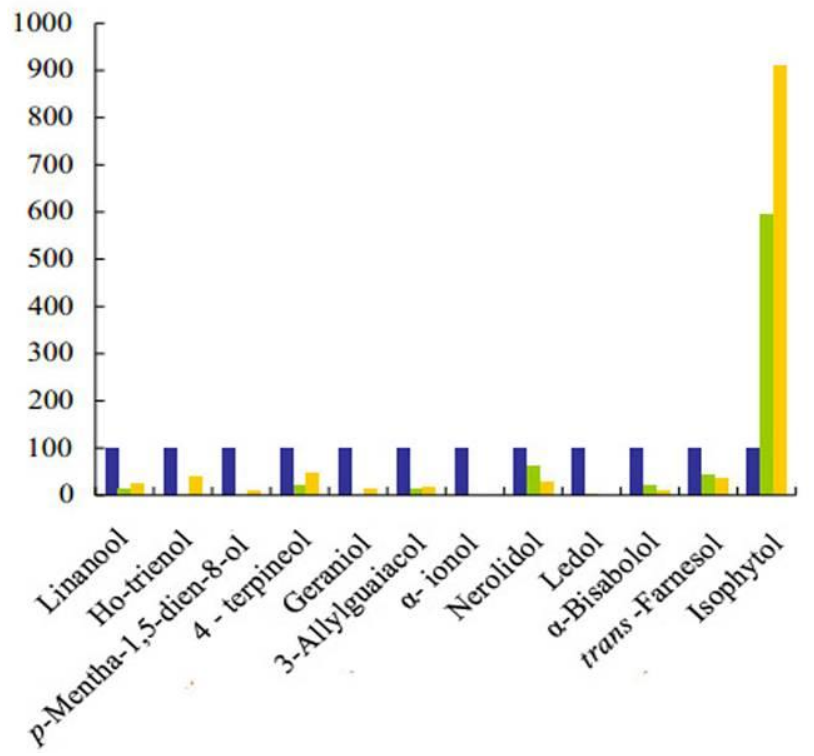

non-fumigated sample

Lab-prepared sulfur-fumigated sample

Industrial sulfur-fumigated sample 
Figure 2. Cont.

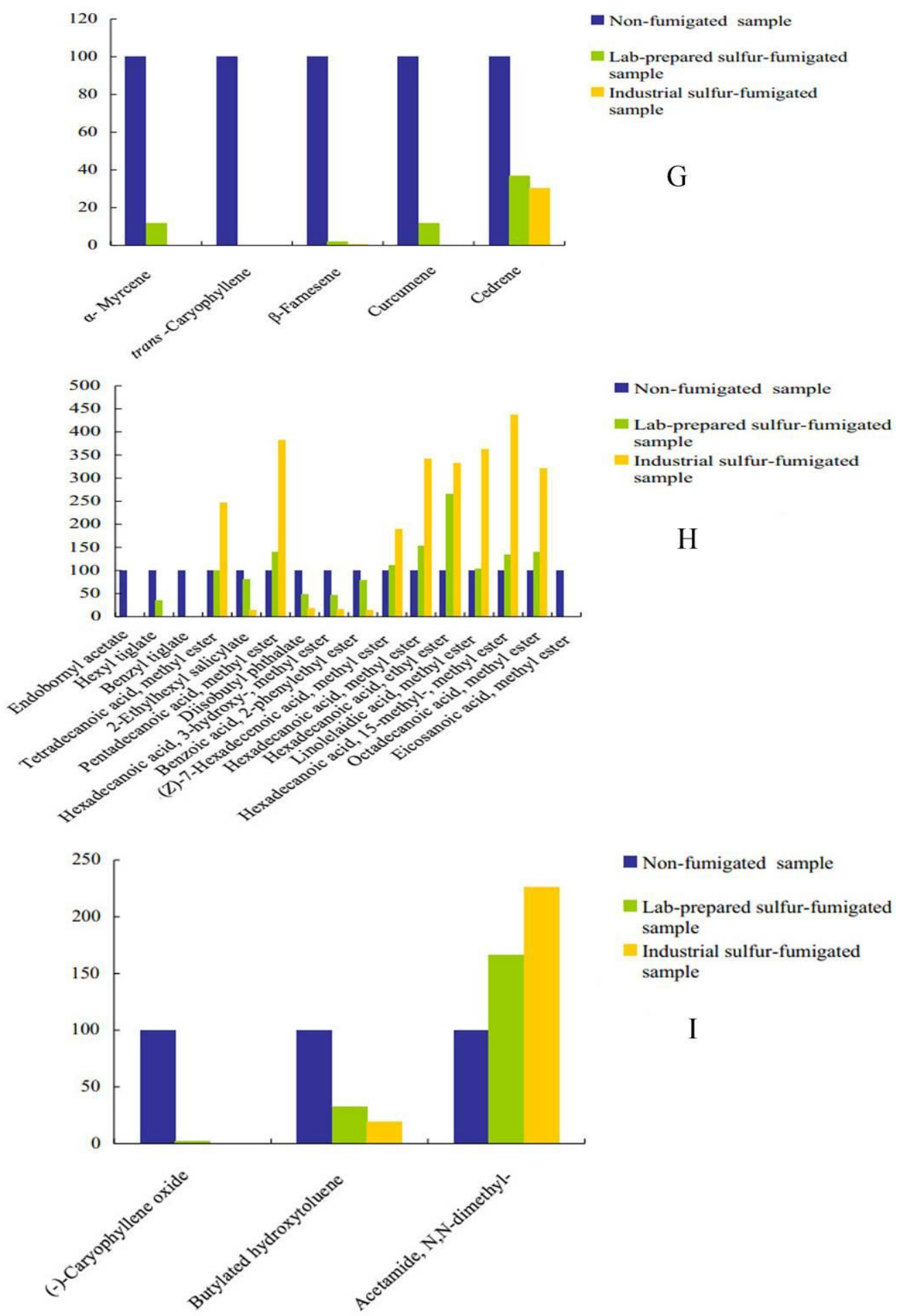

\subsection{Identification of Main Volatile Components in FLJ by GC×GC-TOF/MS}

The mass spectra of features of interest in the TIC can be examined to identify compounds, substructures, and elemental compositions. The GC $\times$ GC-TOF/MS software was used to determine all the peaks in the raw $\mathrm{GC} \times \mathrm{GC}$ chromatograms. In order to further explain automatic peak search and deconvolution of spectrograms in the software information processing of compounds with common outflow characteristics, sections of the identified chemical groups of FLJ samples were included to 
elucidate the principle of relative position in the $2 \mathrm{D}$ chromatogram as shown in Figure 3 . The central portion of the chromatogram showed three compounds, namely curcumene, $\alpha$-ionone and 2,3-dehydro- $\alpha$-ionone, with extremely similar RTs. These three compounds overlapped extensively in the 1D GC chromatogram and could be separated by the second dimension column. The Peak Finding algorithm locates the peaks that appear as a single component in the TIC. The Spectral Deconvolution separates the spectra of these overlapping peaks automatically. Good quality spectra could be produced using the deconvolution algorithm, only made possible with TOF. The structures of these three compounds are shown in Figure 4.

Figure 3. The identified chemical groups of Flos Lonicerae Japonicae volatile oil in the GC $\times$ GC chromatograms and the spectra of 2,3-dehydro- $\alpha$-ionone (A), $\alpha$-ionone $(\mathbf{B})$ and curcumene (C) in sample and in NIST library, respectively (1: Caliper Spectra; 2: Deconvoluted Spectra; 3: NIST Library Spectra).
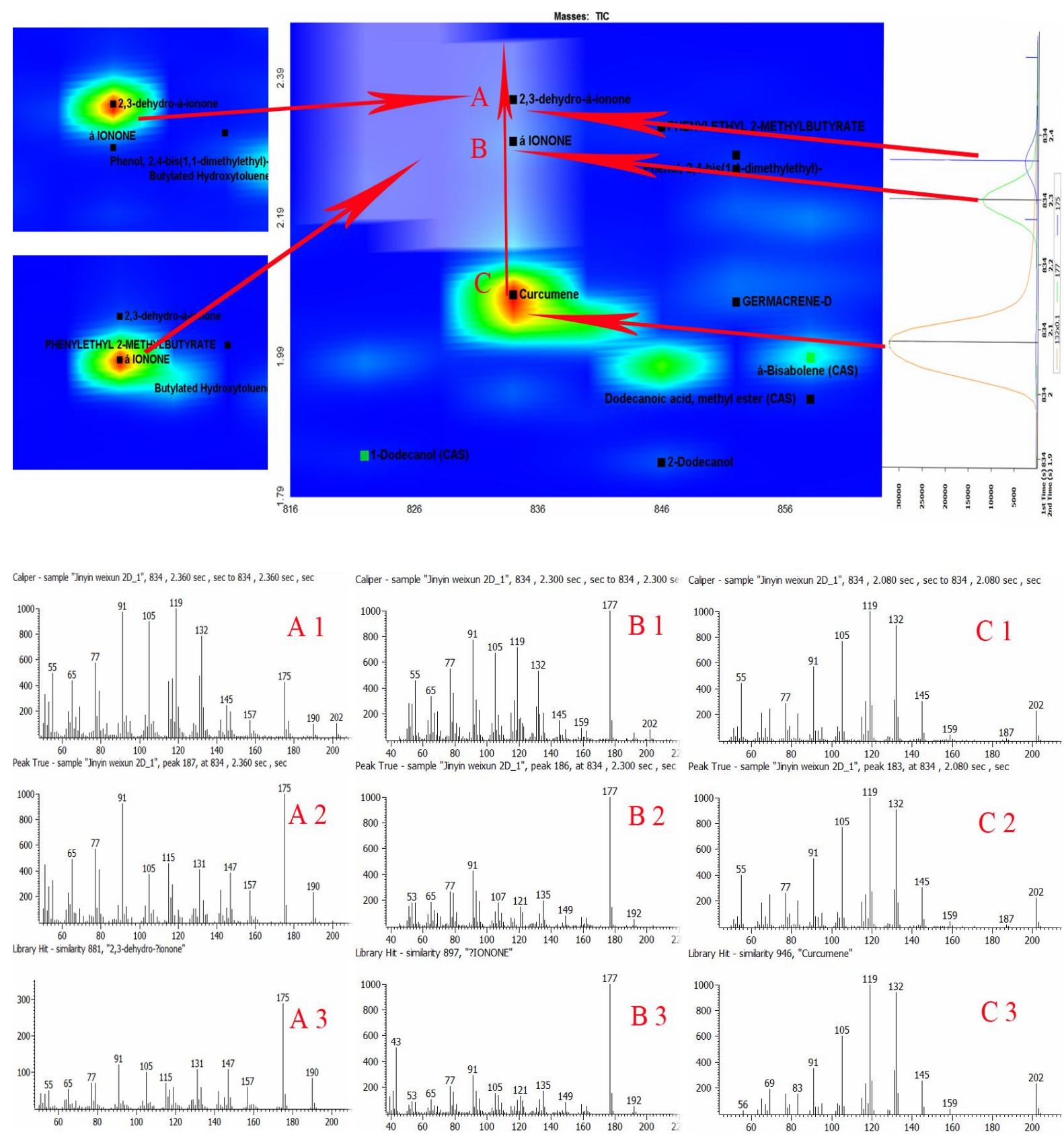
Figure 4. The structures of 2,3-dehydro- $\alpha$-ionone (A), $\alpha$-ionone $(\mathbf{B})$ and curcumene $(\mathbf{C})$.

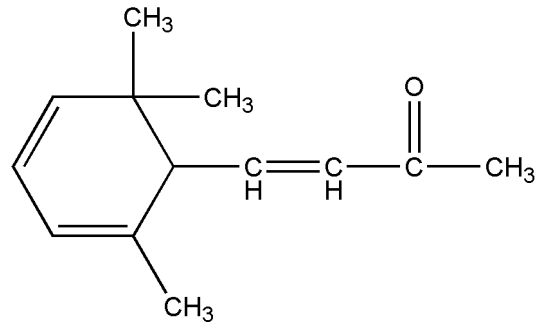

(A)

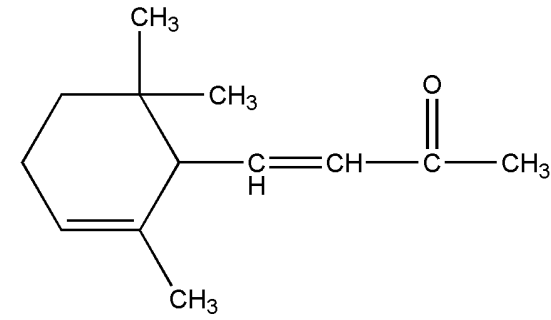

(B)<smiles>CC(C)=CCCC(C)c1ccc(C)cc1</smiles>

(C)

\section{Experimental}

\subsection{Samples and Sample Preparation}

Reference FLJ samples were collected from Shandong province and identified by an expert in the field. The lab-prepared sulfur-fumigated samples were prepared from the reference FLJ samples, following procedures similar to that employed by farmers and wholesalers: The reference FLJ samples $(250 \mathrm{~g})$ were wetted with water $(25 \mathrm{~mL})$, then left standing for $2 \mathrm{~h}$, sulfur powder $(25 \mathrm{~g})$ was heated until burning, the burning sulfur and the wetted reference FLJ samples were carefully put into the lower and upper layer of a desiccator, respectively. The desiccator was then kept closed for $6 \mathrm{~h}$. After fumigation, the lab-prepared sulfur-fumigated FLJ samples were dried in a ventilated drying oven at $40{ }^{\circ} \mathrm{C}$ for $6 \mathrm{~h}$. Moreover, the industrial sulfur-fumigated FLJ samples, which collected from industrial and commercial process, were also used to investigate compared with the reference FLJ samples.

The volatile oils of reference and sulfur-fumigated FLJ were extracted using the steam distillation method (Chinese Pharmacopoeia, Eds. 2010) [19]. The volatile oils obtained were dried over anhydrous sodium sulfate (Sigma, St. Louis, MO, USA), then dissolved in ethyl acetate, the concentrations of reference and sulfur-fumigated FLJ were all about $0.2 \mathrm{~g} / \mathrm{mL}$, and stored in dark glass bottles at $4{ }^{\circ} \mathrm{C}$ until analysis. 


\subsection{GC $\times G C-T O F / M S$ Apparatus}

A LECO time-of-flight (TOF) mass spectrometer model Pegasus 4D (LECO, St. Joseph, MI, USA) connected to an Agilent 6890N GC was used in GC×GC-TOF/MS experiments. An Agilent 7683B autosampler (Agilent, Palo Alto, CA, USA) injected $1.0 \mu \mathrm{L}$ of sample at a split ratio of $20: 1$ at $250{ }^{\circ} \mathrm{C}$ through an inlet onto column 1 . A column set with a non-polar stationary phase primary column and a medium-polar stationary phase secondary column was used. The first dimension chromatographic column was $30 \mathrm{~m} \times 0.25 \mathrm{~mm}, 0.25 \mu \mathrm{m}$ film thickness DB-5ms. The second dimension chromatographic column was $2 \mathrm{~m} \times 0.1 \mathrm{~mm}, 0.1 \mu \mathrm{m}$ film thickness DB-17ht. The columns were connected by means of a press-fit connector, and the two columns were installed in two ovens. Column 1's oven was held at $50{ }^{\circ} \mathrm{C}$ for $1 \mathrm{~min}$, then increased to $180{ }^{\circ} \mathrm{C}$ at a rate of $15^{\circ} \mathrm{C} / \mathrm{min}$ and held for $10 \mathrm{~min}$. The temperature was then further increased to $260{ }^{\circ} \mathrm{C}$ at a rate of $3{ }^{\circ} \mathrm{C} / \mathrm{min}$ and held for $3 \mathrm{~min}$. Column 2 's oven was held at $55^{\circ} \mathrm{C}$ for $1 \mathrm{~min}$, then increased to $185{ }^{\circ} \mathrm{C}$ at a rate of $15{ }^{\circ} \mathrm{C} / \mathrm{min}$, and further increased to $265{ }^{\circ} \mathrm{C}$ at a rate of $3{ }^{\circ} \mathrm{C} / \mathrm{min}$ and held for $3 \mathrm{~min}$. Ultra high purity helium $(99.9995 \%)$ was used as the carrier gas in a constant pressure mode at a flow rate of $1.0 \mathrm{~mL} / \mathrm{min}$. Injector temperature was set at $250{ }^{\circ} \mathrm{C}$ and split mode was used. The transfer line temperature was $250{ }^{\circ} \mathrm{C}$, ion source temperature was $220{ }^{\circ} \mathrm{C}$, detector voltage was $-1850 \mathrm{~V}$, filament bias applied electron ionization voltage at $70 \mathrm{eV}$, and data bunching was set to give a net acquisition rate of $100 \mathrm{~Hz}$ (spectra/s) over the mass range of 45-550 Da. The modulation period was $6 \mathrm{~s}$.

\subsection{Data Processing}

The peaks in the contour plot were integrated and quantified using peak volume. The normalization of peak volume was applied to approximately compare the relative contents of the components due to the lack of standard samples. Data were processed using LECO Pegasus4D software. A S/N threshold of 100 and similarity match threshold of 800 (on the scale of 1-999) was used for peak detection and identification. Identification of compounds was achieved by comparing the experimental (TOF/MS) spectra with NIST08, Adams and Wiley 6 database libraries, and supported by experimentally determined retention index (RI) values, when available. The results of the analyses are located in the peak table. All statistical analyses were conducted using JMP version 7.0.1 (SAS Institute Inc., Cary, NC, USA).

\section{Conclusions}

The present study has described the development of a sensitive and comprehensive method for analyzing volatile compounds found in non-fumigated and sulfur-fumigated Flos Lonicerae Japonicae through the use of GC $\times$ GC-TOF/MS. This study is first successfully applied to GC $\times$ GC-TOF/MS analysis of volatile compounds in sulfur-fumigated Flos Lonicerae Japonicae. Compared to the previous studies using one-dimensional GC-MS, GC $\times \mathrm{GC}$ showed higher resolving power and peak capacity. 73 representative volatile compounds with match quality greater than $80 \%$ were identified in non-fumigated and sulfur-fumigated Flos Lonicerae Japonicae samples. The established method was successfully applied for the rapid identification of sulfur-fumigated Flos Lonicerae Japonicae in commercial FLJ samples. The proposed assay provides an important reference, and can be readily 
utilized as a suitable method for rapid and accurate quality evaluation of Flos Lonicerae Japonicae and related medicinal materials.

\section{Acknowledgements}

The authors are grateful for the financial support of the National Natural Science Foundation of China (No. 81173546, No. 30940093, No. 81202918 and 81274056), the Natural Science Foundation of Jiangsu Province, China (No. BK2009495), the International Science and Technology Cooperation Project of Jiangsu Province, China (No. BZ2011053), the Open Project of National First-Class Key

Discipline for Science of Chinese Materia Medica, Nanjing University of Chinese Medicine (No. 2011ZYX2-006, No. 2011ZYX2-001), the fund of Zhejiang Modernization of Traditional Chinese Medicine Item ([2008]436), and the Chinese Medicine Research Program of Zhejiang Province, China (2008ZA002).

\section{Conflict of Interest}

The authors have declared no conflict of interest.

\section{References}

1. Ren, M.T.; Chen, J.; Song, Y.; Sheng, L.S.; Li, P.; Qi, L.W. Identification and quantification of 32 bioactive compounds in Lonicerae species by high performance liquid chromatography coupled with time-of-flight mass spectrometry. J. Pharm. Biomed. Anal. 2008, 48, 1351-1360.

2. Qian, Z.M.; Wen, X.D.; Li, H.J.; Liu, Y.; Qin, S.J.; Li, P. Analysis of interaction property of bioactive components in Flos Lonicerae Japonicae with protein by microdialysis coupled with HPLC-DAD-MS. Biol. Pharm. Bull. 2008, 31, 126-130.

3. Chen, X.; Xia, Y.; Lu, Y.; Liang, J. Screening of permeable compounds in Flos Lonicerae Japonicae with liposome using ultrafiltration and HPLC. J. Pharm. Biomed. Anal. 2011, 54, 406-410.

4. Hu, F.L.; Deng, C.H.; Liu, Y.; Zhang, X.M. Quantitative determination of chlorogenic acid in Honeysuckle using microwave-assisted extraction followed by nano-LC-ESI mass spectrometry. Talanta 2009, 77, 1299-1303.

5. Li, S.L.; Shen, H.; Zhu, L.Y.; Xu, J.; Jia, X.B.; Zhang, H.M.; Lin, G.; Cai, H.; Cai, B.C.; Chen, S.L.; $\mathrm{Xu}, \mathrm{H}$.X. Ultra-high-performance liquid chromatography-quadrupole/time of flight mass spectrometry based chemical profiling approach to rapidly reveal chemical transformation of sulfur-fumigated medicinal herbs, a case study on white ginseng. J. Chromatogr. A 2012, 1231, 31-45.

6. Duan, B.Z.; Huang, L.F.; Chen, S.L. Study on the destructive effect to inherent quality of Fritillaria thunbergii Miq. (Zhebeimu) by sulfur-fumigated process using chromatographic fingerprinting analysis. Phytomedicine 2012, 19, 562-568.

7. Shui, G.; Leong, L.P. An improved method for the analysis of major antioxidants of Hibiscus esculentus Linn. J. Chromatogr. A 2004, 1048, 17-24.

8. Tang, D.; Li, H.J.; Chen, J.; Guo, C.W.; Li, P. Rapid and simple method for screening of natural antioxidants from Chinese herb Flos Lonicerae Japonicae by DPPH-HPLC-DAD-TOF/MS. J. Sep. Sci. 2008, 31, 3519-3526. 
9. Shui, G.; Leong, L.P. Screening and identification of antioxidants in biological samples using high-performance liquid chromatography-mass spectrometry and its application on Salacca edulis Reinw. J. Agric. Food Chem. 2005, 53, 880-886.

10. Shui, G.; Leong, L.P.; Wong, S.P. Rapid screening and characterisation of antioxidants of Cosmos caudatus using liquid chromatography coupled with mass spectrometry. J. Chromatogr. B 2005, 827, 127-138.

11. Chen, X.G.; Hu, L.H.; Su, X.Y.; Kong, L.; Ye, M.L.; Zou, H.F. Separation and detection of compounds in Honeysuckle by integration of ion-exchange chromatography fractionation with reversed-phase liquid chromatography-atmospheric pressure chemical ionization mass spectrometer and matrix-assisted laser desorption/ionization time-of-flight mass spectrometry analysis. J. Pharm. Biomed. Anal. 2006, 40, 559-570.

12. Qi, L.W.; Chen, C.Y.; Li, P. Structural characterization and identification of iridoid glycosides, saponins, phenolic acids and flavonoids in Flos Lonicerae Japonicae by a fast liquid chromatography method with diode-array detection and time-of-flight mass spectrometry. Rapid Commun. Mass Spectrom. 2009, 23, 3227-3242.

13. Cao, G.; Shan, Q.Y.; Li, X.M.; Cong, X.D.; Zhang, Y.; Cai, H.; Cai, B.C. Analysis of fresh Mentha haplocalyx volatile components by comprehensive two-dimensional gas chromatography and high-resolution time-of-flight mass spectrometry. Analyst 2011, 136, 4653-4661.

14. Ma, C.F.; Wang, H.H.; Lu, X.; Li, H.F.; Liu, B.Y.; Xu, G.W. Analysis of Artemisia annua L. volatile oil by comprehensive two-dimensional gas chromatography time-of-flight mass spectrometry. J. Chromatogr. A 2007, 1150, 50-53.

15. Schoenmaker, P.J.; Oomen, J.L.; Blomberg, J.; Genuit, W.; van Velzen, G. Comparison of comprehensive two-dimensional gas chromatography and gas chromatography-mass spectrometry for the characterization of complex hydrocarbon mixtures. J. Chromatogr. A 2000, 892, 29-46.

16. Ong, R.C.; Marriott, P.J. A review of basic concepts in comprehensive two-dimensional gas chromatography. J. Chromatogr. Sci. 2002, 40, 276-291.

17. Qiu, Y.Q.; Lu, X.; Pang, T.; Ma, C.F.; Li, X.; Xu, G.W. Determination of radix ginseng volatile oils at different ages by comprehensive two-dimensional gas chromatography/time-of-flight mass spectrometry. J. Sep. Sci. 2008, 31, 3451-3457.

18. Djozan, D.; Baheri, T.; Farshbaf, R.; Ashari, S. Investigation of solid-phase microextraction efficiency using pencil lead fiber for in vitro and in vivo sampling of defensive volatiles from insect's scent gland. Anal. Chim. Acta 2005, 554, 197-201.

19. Pharmacopoeia of the People's Republic of China; China Medical Science Press: Beijing, China, 2010; Volume 1, Appendix XD, p. 63.

Sample Availability: Samples of Flos Lonicerae Japonicae are available from the authors.

(C) 2013 by the authors; licensee MDPI, Basel, Switzerland. This article is an open access article distributed under the terms and conditions of the Creative Commons Attribution license (http://creativecommons.org/licenses/by/3.0/). 